This is a post-referring accepted version. Please refer to the published version when citing:

Cohen, E. \& Cohen, S.A. (2015). Tourism mobilities from emerging world regions: A response to commentaries. Current Issues in Tourism, 18(1), 68-69, DOI: 10.1080/13683500.2014.956705.

\title{
Tourism mobilities from emerging world regions: A response to commentaries
}

\section{Professor Erik Cohen}

George S. Wise Professor of Sociology (emeritus)

The Hebrew University of Jerusalem, Israel

Dept. of Sociology and Anthropology, The Hebrew University of Jerusalem, 91905, Israel, mserik@mscc.huji.ac.il

Dr Scott A. Cohen

Senior Lecturer in Tourism

University of Surrey, United Kingdom

School of Hospitality and Tourism Management, Faculty of Business Economics and Law, University of Surrey, Guildford, GU2 7XH, United Kingdom, s.cohen@surrey.ac.uk

Keywords: emerging regions, business mobilities, power, immobility

In Cohen and Cohen (2014), "A mobilities approach to tourism from emerging world regions", we attempted to move beyond the Eurocentric bias in tourism studies (see Cohen \& Cohen [2015] on Eurocentrism in tourism research) by applying a modified version of the mobilities paradigm to the comparative study of tourism from Asia, the Middle East, Latin America and sub-Saharan Africa. Here we respond to the three commentaries on Cohen and Cohen (2014) published in this issue. We thank the commentators - Chris Rogerson, Jingfu Chen and T.C. Chang, and Tim Coles for their interest, insightful comments and innovative analyses. We are gratified to note that all commentators appreciated our effort to create a platform for the comparison of Western tourism with that from the emerging regions; however, while not offering a fundamental criticism, they raised several significant points, which might 
help to deepen and expand our analysis. These relate primarily to three issues, which we address in turn: the incorporation of business mobilities into the study of tourism from the emerging regions (Rogerson, 2014), the call to deepen the analysis of power in the study of "non-Western" tourism (Chen and Chang, 2014) and the need to incorporate into the analysis the less mobile population of these parts of the world (Coles, 2014).

1. Business mobilities. Rogerson (2014) raises some valuable points in his detailed presentation of formal, and especially non-formal, business mobilities in sub-Saharan Africa. We agree that business travel frequently includes a variety of leisure activities. We have not specifically related to it because we restricted our analysis to "discretionary mobilities", a concept which widens the conventional connotation of "tourism", but largely precludes an incorporation of forms of corporeal mobility driven primarily by necessity rather than choice, such as business travel, labor migration, diplomatic journeys or military movements. Rogerson's paper usefully extends the analysis beyond discretionary mobilities to include business mobilities, and unpacks some of the ways in which discretionary and business mobilities are enfolded. His perspective feeds well into Chen and Chang's (2014) concern that the concept of discretionary mobilities implies a binary, there being no such thing as 'free bodies on the move'. We do not contend that discretionary mobilities are completely optional or voluntary in an etic sense. We recognize that the concept of "discretionary mobilities" has fuzzy boundaries, but believe that it has an easily recognizable core connotation of voluntariness, making it applicable on a global comparative level.

2. Power. We gave attention to the dimensions of both economic and political power in the mobilities regimes of the various countries in the emerging regions. These dimensions are implicit in Cresswell's (2010) concept of "mobility constellations" and crucial to that of "kinetic hierarchies", which we have widely used in our analysis. In fact, we have even related to the changing restrictive measures, taken by the Chinese authorities, to regulate outbound tourism, mentioned by Chen and Chang (2014). We consent, however, that we did not investigate in depth the economic and political forces by which these constellations and hierarchies have been constituted. This is a huge task, which would involve broad and detailed historical analysis for each region or countries within it, which is far beyond our competencies; but we shall be happy, if such studies would be instigated by our presentation. 
3. Immobility. Since we chose the topic of tourism in the emerging regions we inherently prioritized the study of the more mobile over the less mobile parts of their populations. To be sure, we implicitly related to the latter, on the analytical level by discussing the shape of the slanted "kinetic hierarchies" in those regions, and on the empirical level, by pointing out the restriction of outbound travel to a very limited percentage of the total population in most countries in those regions. Admittedly, we did not investigate in detail the social and economic factors which restrict discretionary travel to a small minority of their populations. But this does not necessarily imply that a mobilities approach to tourism in emerging regions is in some way inappropriate, or unable to account for the "frictions" or "blockages", which impede the mobility of the broader population strata. In concluding we noted as a limitation of our article that we rarely explicitly discussed points of friction. We agree that the study of the immobilities of persons from the emerging regions are a key topic of further study.

As a final point, while we also agree that such studies as the relationship of tourism and climate change, mentioned by Coles (2014), are of high practical significance, they seem to be a poor theoretical substitute for the mobilities approach to the comparative study of global tourism. Hence, the intimation that a mobilities approach is already passé, before it was even widely adopted in the study of tourism, seems to be somewhat premature. Contrariwise, it may be that the application of a mobilities approach to the study of important contemporary problems, such as the relationship between mobilities from the emerging world regions and environmental change is one of the manifold important directions that mobilities research might take in the near future.

\section{References}

Chen, J. \& Chang, T.C. (2014). Mobilising tourism research in emerging world regions: Contributions and advances. Current Issues in Tourism (In press)

Cohen, E. \& Cohen, S.A. (2014). A mobilities approach to tourism from emerging world regions. Current Issues in Tourism, DOI: 10.1080/13683500.2014.898617.

Cohen, E. \& Cohen, S.A. (2015). Beyond Eurocentrism in tourism: A paradigm shift to mobilities. Tourism Recreation Research, 40(1) (forthcoming)

Coles, T. (2014). Tourism mobilities: Still a current issue in tourism? Current Issues in Tourism (In press) 
Cresswell, T. (2010). Towards a politics of mobility. Environment and Planning D: Society and Space, 28, 17-31.

Rogerson, C.M. (2014). Unpacking business tourism mobilities in sub-Saharan Africa. Current Issues in Tourism, DOI: 10.1080/13683500.2014.898619. 